\title{
ОТРАЖЕНИЕ АУТЕНТИЧНЫХ МАТЕРИАЛОВ В УЧЕБНЫХ ПОСОБИЯХ ПО АНГЛИЙСКОМУ ЯЗЫКУ, ПРЕДНАЗНАЧЕННЫХ ДЛЯ СЛУШАТЕЛЕЙ ВОЕННЫХ АКАДЕМИЙ
}

\section{THE REFLECTION OF AUTHENTIC MATERIALS IN THE ENGLISH LANGUAGE TEACHERS DESIGNED FOR LISTENERS OF MILITARY ACADEMIES}

\section{Ostreiko}

Summary: The article is devoted to the description of a textbook on English for students of military academies. The main attention in the work is paid to the characteristics of the USA engineering forces. The main purpose of the work is to present an approximate plan of the training manual, as well as tasks aimed at improving the understanding of authentic texts, the ability to formulate their thoughts and tell the necessary information about the engineering troops and their features. The article presents the literature that can be used in the classroom in English, including scientific journals, a glossary and textbooks intended for students of military academies.

Keywords: authentic texts, students of military academies, USA engineers, English.

\author{
Острейко Лариса Владимировна \\ Дочент, Общевойсковая ордена Жукова Академия ВС РФ \\ larisa-vl@list.ru
}

Аннотация: Статья посвящена описанию учебного пособия по английскому языку для слушателей военных академий. Основное внимание в работе уделено характеристике инженерных войск (ША. Главной целью работы является представление примерного плана учебного пособия, а также заданий, направленных на улучшение понимания аутентичных текстов, умения формулировать свои мысли и рассказывать необходимую информацию об инженерных войсках и их особенностях. В статье представлена литература, которую можно применять на занятиях по английскому языку, включающая в себя научные журналы, глоссарий и учебники, предназначенные для слушателей военных академий.

Ключевые слова: аутентичные тексты, слушатели военных академий, инженерные войска США, английский язык.
B процессе обучения иностранному языку слушателей военных академий особое внимание уделяется проблеме использования аутентичных профессионально значимых учебных текстов. Современная методика преподавания иностранного языка в военном вузе строится на базе коммуникативного подхода, в рамках которого необходимо максимально приблизить процесс обучения языку к процессу живого общения.

Как отмечает Н.А. Гриднева, главной трудностью использования аутентичных текстов на занятиях является несоответствие уровня языковой сложности аутентичных материалов уровню языковой подготовки обучающихся [2, с. 76]. Актуальность работы обусловлена потребностью создания учебных пособий по английскому языку, разработанных в соответствии с особенностями специализации слушателей военных академий.

Целью данной работы является создание приблизительного тематического плана и примеров упражнений по английскому языку для слушателей военных академий, изучающих инженерные войска армии США.

Научной новизной работы является создание примерного тематического плана для подготовки учебного пособия по английскому языку в военном вузе.

Практическая ченность данной статьи заключается в том, что эти материалы можно использовать для создания учебно-практического издания по английскому языку в военном вузе и использовать его на практических и самостоятельных занятиях со слушателями военных академий.

Указ «Об установлении Дня инженерных войск» был подписан Президентом РФ 18 сентября 1996 года. Однако впервые инженерные войска были созданы 21 января 1701 года Указом Петра I о создании в Москве Школы пушкаркого приказа, в которой готовили офицеров артиллерии и военных инженеров [3, с. 46].

На сегодняшний день группой специалистов из разных стран под руководством Оборонной академии Канады и Колледжа вооруженных сил Швейцарии по поручению НАТО разработан «Типовой учебный план по военно-профессиональной подготовке сержантского состава». В данном пособии представлено четыре уровня: 1) начальный; 2) промежуточный; 3) продвинутый; 4) старший командир рядового и сержантского состава. В работе имеется три основных предмета: 1) «Профессия 
кадрового военного»; 2) Командирские навыки и этика»; 3) «Основные качества и навыки сержантского состава» [5, с. 5]. Каждая тема разделена на небольшие модули, в рамках которых представлено описание, особенности методики обучения и оценки, задачи и результаты обучения, вопросы для рассмотрения, а также справочная литература.

В новое учебное пособие по английскому языку можно взять задачи и результаты обучения. В качестве примера можно привести следующее задание: перевести фразу «рассказать, каким образом офичер и сержант поддерживают профессиональные отношения между командиром и подчиненными». Составить текст, в котором офицер обращается к аудитории с целью донесения информации о профессиональном общении. Сформулировать вопросы военных, которым объясняется эта тема.

В учебном пособии, посвященном характеристике инженерных войск армии США необходимо выделить следующие тематические разделы: 1) история становления инженерных войск; 2) командиры инженерных войск; 3) военные миссии (строительство, полевая инженерия, медицинское оборудование); 4) обеспечение военных действий; 5) применение инженерных войск. Особое внимание необходимо обратить на задачи инженерных войск, инженерную роту бронекавалерийского полка США, возможности роты по выполнению основных задач (установление противотанковых рвов, мостовых переходов через препятствия, др.), инженерный батальон, инженерную бригаду, инженерную бригаду АК США и выполняемые функции данных бригад.

Слушателям военных академий необходимо различать специализированную технику, используемую при выполнении основных функций инженерными войсками: танковые мостоукладчики, универсальные инженерные машины, экскаваторы, разборные мосты, ковшовые погрузчики, бульдозеры, автогрейдеры и др. В учебном пособии можно разместить рисунки специализированной техники, выучить их самостоятельно дома и уметь использовать в тематическом диалоге.

В учебнике под редакцией Ю.Б. Торгованова представлены виды войск Российской армии, а также тактическая подготовка слушателей военных академий. Этот учебник интересен описанием применения инженерных войск в России. В нем указано, что инженерные войска способны обеспечить высокие темпы наступления, в том числе с использованием минно-взрывных заграждений [4, с. 14]. Небольшие тексты, представленные в этом учебнике, посвященные обеспечению военных действий, можно поместить в четвертый и пятый раздел учебного пособия. Здесь могут быть представлены переработанные небольшие отрывки на русском языке, которые необходимо будет перевести на английский. К этим текстам можно подобрать следующее задание: Report to the commander about the readiness of the Engineers. Tell him about the location of the minefield. Кроме этого, можно составить диалог между сержантом и солдатами, в котором сержант дает распоряжение, требующее обязательного исполнения.

Интерес представляет учебное пособие Р.Р. Ахметова, в котором подробно описываются роль инженерного обеспечения боевых действий иностранных войск, средства инженерного вооружения и перспективы развития, организация и возможности инженерных войск разных стран. Пособие составлено на русском языке, представляет собой теоретическое описание инженерного обеспечения боевых действий сухопутных войск [1, с. 102]. Корпус инженеров США создан с целью планирования и строительства объектов для сухопутного назначения, планирования закупок, эксплуатации, ремонта зданий и сооружений. В учебном пособии можно использовать следующее задание: вставить пропущенные слова «According to organizational affiliation, engineering troops are divided into military and ... (strategic reserves). (Military engineering) formations are included in the staff of combined arms units. The (strategic reserve) is intended to strengthen the army corps». Задания, направленные на дополнение английских предложений необходимыми по смыслу словами и выражениями, помогают усвоению новых терминов, умению использовать их в контексте военной терминологии.

Особое внимание хочется отметить на понимании организационной структуры инженерных войск США. Слушателям военных академий можно предложить составить схему состава инженерного корпуса и обозначить структуру командования: divisional engineer brigade (battalion) commander (divisional engineer), commander of an engineering battalion of a separate brigade, engineering team, corps engineer, headquarters engineering section, headquarters, headquarters company. Основные понятия: company, battalion, brigade.

Как отмечает Р.Р. Ахметов, главными задачами инженерного обеспечения инженерных войск США являются следующие: 1) мобильность (преодоление заграждений противника); 2) контрмобильность (усиление местности, постановка заграждений); 3) живучесть (снижение потерь от средств поражения противника); 4) общие инженерные задачи (ведение инженерной разведки) [1, с. 5]. К заданиям повышенной сложности можно отнести распределение задач по четырем категориям (табл. 1.).

Перед выполнением задания необходимо дать четкое представление о различиях выполняемых функций, сформулировать ключевые слова и опорные фразы. В представленной таблице характеристика задач совпадает с их названием, однако слушателей военных ака- 
Таблица 1.

Категории задач инженерного обеспечения

\begin{tabular}{|l|l|l|l|}
\hline \multicolumn{1}{|c|}{ mobility } & \multicolumn{1}{|c|}{ countermobility } & \multicolumn{1}{c|}{ vitality } \\
\hline $\begin{array}{l}\text { planning and conducting engineering } \\
\text { measures to overcome enemy } \\
\text { obstacles }\end{array}$ & $\begin{array}{l}\text { setting up obstacles and devices that } \\
\text { interfere with enemy actions }\end{array}$ & $\begin{array}{l}\text { engineering measures to reduce losses } \\
\text { from all means of destruction }\end{array}$ & engineering intelligence \\
\hline $\begin{array}{l}\text { overlapping of obstacles with assault } \\
\text { bridges preparation and maintenance } \\
\text { of column tracks }\end{array}$ & $\begin{array}{l}\text { obstacles should be closely linked } \\
\text { to natural obstacles and among } \\
\text { themselves }\end{array}$ & camouflage & preparation of column tracks and roads \\
\hline bypass construction & $\begin{array}{l}\text { the system of obstacles should } \\
\text { be made taking into account the } \\
\text { preservation of the ability to maneuver } \\
\text { its troops }\end{array}$ & $\begin{array}{l}\text { creation of false objects of elements of } \\
\text { battle formation }\end{array}$ & construction of airfields and helipads \\
\hline strengthening bridges & $\begin{array}{l}\text { mine-explosive obstacles must be } \\
\text { created and used to the full depth of } \\
\text { the combat zones of the brigades }\end{array}$ & $\begin{array}{l}\text { protection against precision } \\
\text { weapons and participation in the } \\
\text { implementation of common plan to } \\
\text { mislead the enemy }\end{array}$ & restoration of protective structures \\
\hline
\end{tabular}

демий можно попросить выполнить задание соотнести названия категорий задач и его расшифровок.

После знакомства с теоретической частью каждой темы и выполнения соответствующих заданий слушателям военных академий можно предложить ответы на вопросы. В качестве примера можно привести следующие:

1. Tell us about mobility as one of the missions of the USA Corps of Engineers.

2. Report to the commander about the implementation of the counter-mobility of the engineering troops.

3. List the melting means used in engineering exploration (engineering vehicles, transporters, remote controlled ferries).

После устных или письменных ответов на вопросы слушателям военных академий можно предложить следующий раздел: it is important to know. В этот раздел можно поместить основные вопросы пройденной темы:

1. The role of engineering support for combat operations of troops, requirements for him and the most important principles.

2. Purpose, basic principles of the organizational structure and combat use of engineering troops.

3. Means of engineering weapons and prospects for their development.

При составлении учебного пособия необходимо обратить внимание на создание глоссария, в состав которого необходимо включить написание термина, транскрипция, перевод, пример употребления, перевод на русский язык. Интерес представляет «Сводный глоссарий совета Россия - НАТО по сотрудничеству» [6]. В него вошла согласованная терминологическая база совета Россия - НАТО. Словарная статья предполагает графическое написание термина, перевод на русский язык, при- мер употребления в тексте с переводом.

В учебном пособии может быть глоссарий, который необходим для составления пересказов текстов, работы в парах, диалогов и проч. формам работы. Материалы научно-практического журнала «Армейский вестник» могут быть использованы в виде аутентичных текстов на русском языке. Данные тексты можно переводить на английский язык, используя соответствующий словарь.

В качестве Интернет-ресурса с размещенными аутентичными текстами хотелось бы порекомендовать Вебсайт Инженерного корпуса армии США. Здесь расположена информация о становлении инженерных войск в США, командиров, экспонатов, исторических образах, миссии, строительство, программы управления рисками наводнений и безопасности дамб и др. В этих текстах отражена специфика инженерных войск [7].

Таким образом, нам удалось выявить специфические четы инженерных войск, составить небольшой план учебного пособия по английскому языку, посвященного работе с инженерными войсками. В этой работе мы проанализировали имеющиеся пособия, в которых отражена специфика инженерных войск. Слушателям военных академий будет предложено изучить теоретический материал, ответить на вопросы после получения темы, выучить слова, необходимые для составления диалогов и полилогов в рамках аудирования.

Отметим, что в рамках одной статьи сложно представить весь тематический план составления учебного пособия, однако мы привели упражнения, которых нет в анализируемых учебниках, представили возможности для использования аутентичных текстов на занятиях по английскому языку. 


\section{ЛИТЕРАТУРА}

1. Ахметов Р.Р. Инженерные войска иностранных армий: учебное пособие. Омск: СибАдИ, 2011. 102 с.

2. Гриднева Н.А. Использование аутентичных материалов в обучении иностранному языку на уровне А1 // Самарский научный вестник. 2017. Т. 6. № 4 (21). C. 76-81.

3. Сосницкий В., Муравьев Г., Торубара А. Инженерные войска: вчера, сегодня, завтра // Армейский сборник. Научный практико-методический журнал. Январь 2016. № 1. С. 46-50.

4. Тактическая подготовка курсантов учебных военных центров: учебник / Ю.Б. Торгованов и др; ред. Ю.Б. Торгованов. Красноярск: Сиб. федер. ун-т, 2014. 552 c.

5. Типовой учебный план по военно-профессиональной подготовке сержантского состава / Коллектив авторов. Канада, 10 октября 2013. 192 с.

6. NATO-Russia Council Consolidated Glossary of Cooperation. Brussels-Moscow, 2011. 368 c.

7. United States Army Corps of Engineers [Электронный pecypc]. URL: https://www.usace.army.mil/ Дата обращения: 11.02.2021.

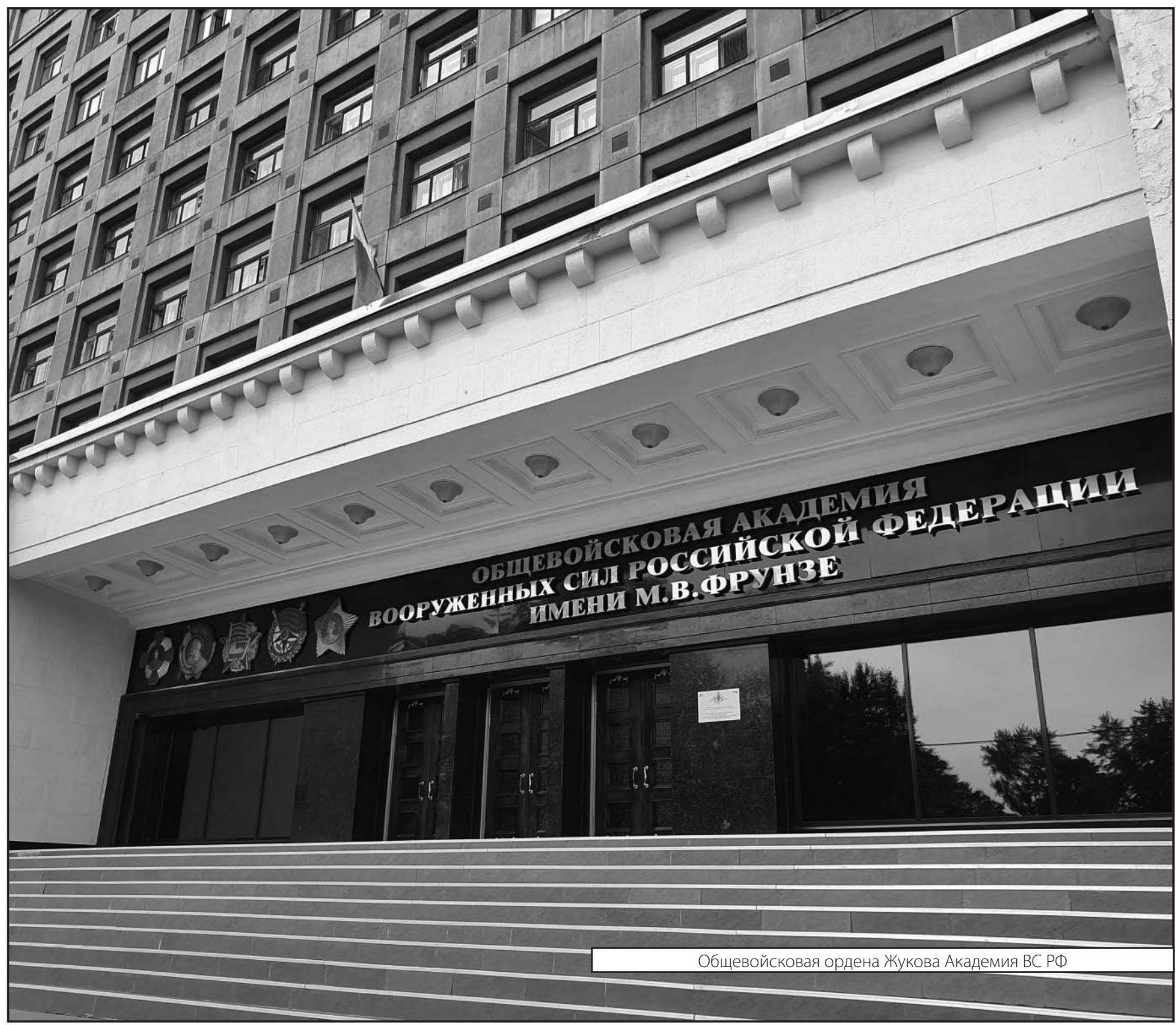

